\title{
After Action Report: Idaho National Lab 2017 Exercise September 20, 2017
}

November 2017

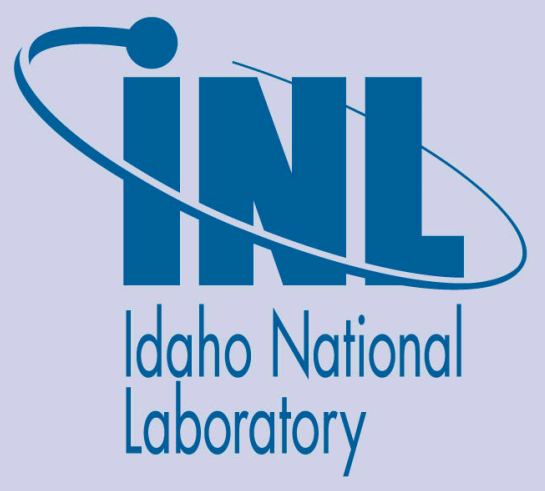

The INL is a U.S. Department of Energy National Laboratory operated by Battelle Energy Alliance 


\section{DISCLAIMER}

This information was prepared as an account of work sponsored by an agency of the U.S. Government. Neither the U.S. Government nor any agency thereof, nor any of their employees, makes any warranty, expressed or implied, or assumes any legal liability or responsibility for the accuracy, completeness, or usefulness, of any information, apparatus, product, or process disclosed, or represents that its use would not infringe privately owned rights. References herein to any specific commercial product, process, or service by trade name, trade mark, manufacturer, or otherwise, does not necessarily constitute or imply its endorsement, recommendation, or favoring by the U.S. Government or any agency thereof. The views and opinions of authors expressed herein do not necessarily state or reflect those of the U.S. Government or any agency thereof. 


\section{After Action Report: Idaho National Laboratory 2017 Annual Exercise September 20, 2017}

November 2017

Idaho National Laboratory Idaho Falls, Idaho 83415

Prepared for the U.S. Department of Energy Under DOE Idaho Operations Office

Contract DE-AC07-05ID14517 
INTENTIONALLY LEFT BLANK 


\section{Emergency Management}

\section{After Action Report: Idaho National Laboratory 2017 Annual Exercise September 20, 2017}

INL/EXT-17-43701

November 2017

Submitted by Scott Barnes Drill Director

Approved by Carl J. Farmer

INL Emergency Management Manager
Date

Date 
INTENTIONALLY LEFT BLANK 


\section{CONTENTS}

ACRONYMS

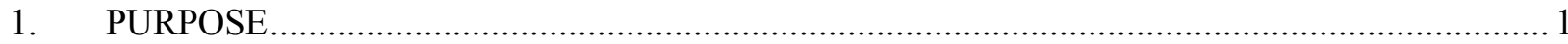

2. SCOPE

INL Emergency Response Organizations (EROs) ….................................................... 1

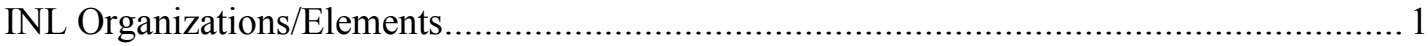

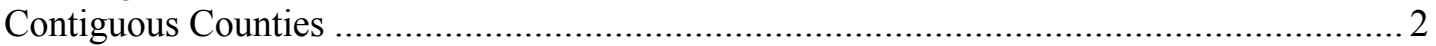

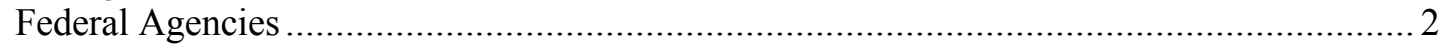

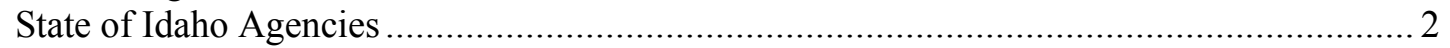

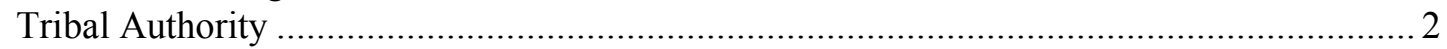

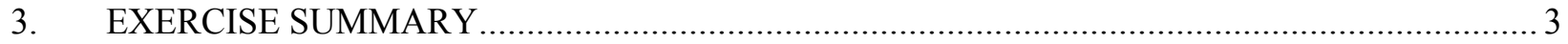

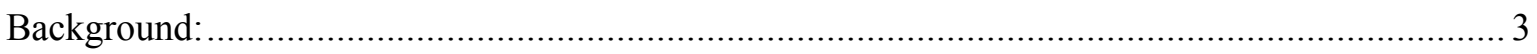

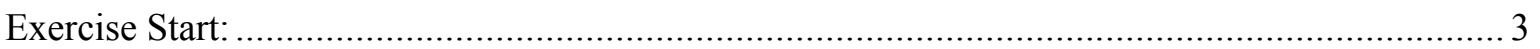

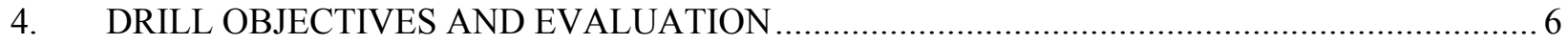

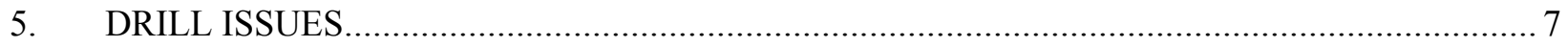

5.1 Emergency Response Organization Response …................................................... 7

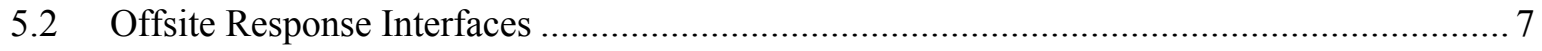

5.3 Emergency Event Categorization and Classification .................................................. 8

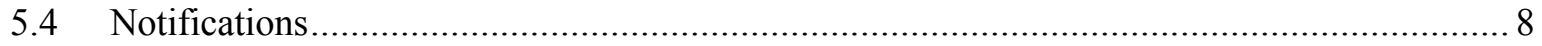

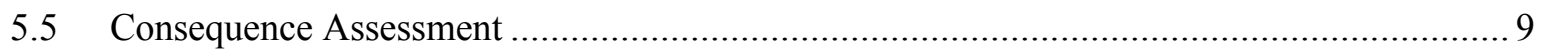

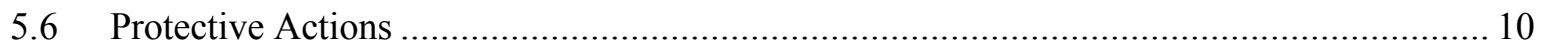

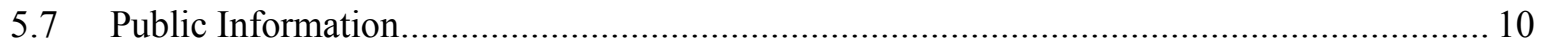

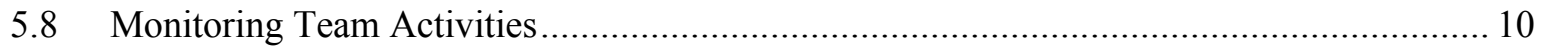

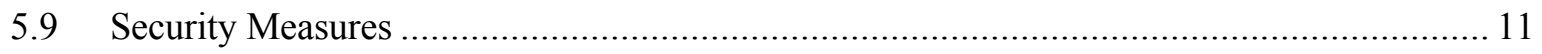

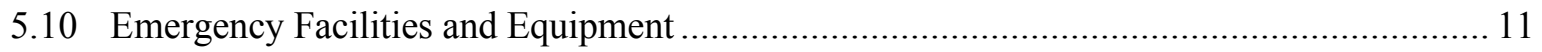

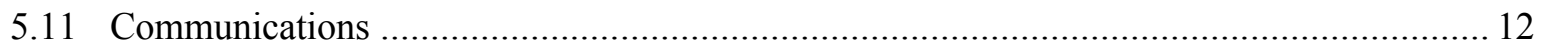

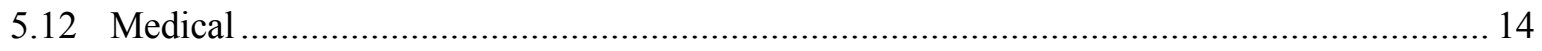

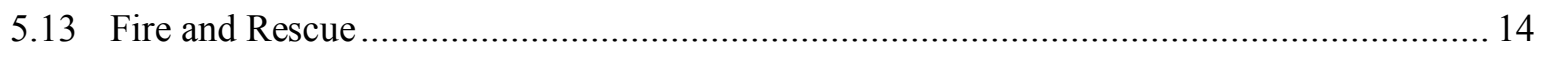

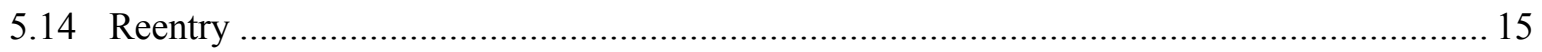

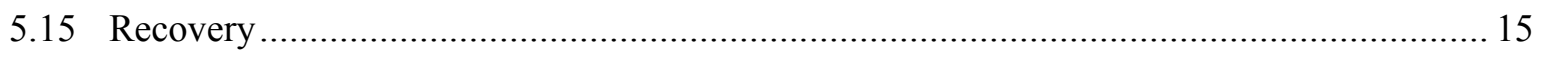

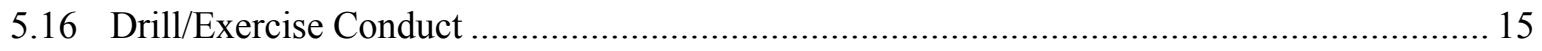

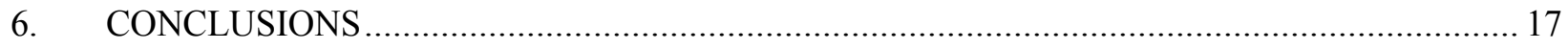

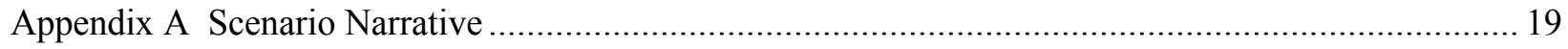

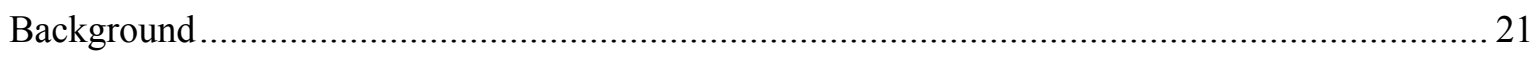

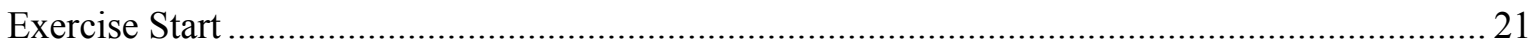




\section{TABLES}

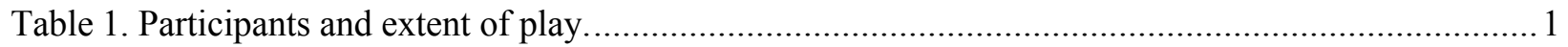

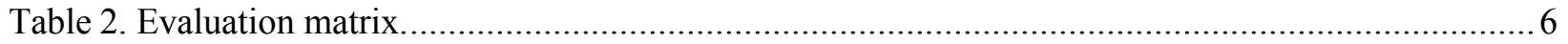




\section{ACRONYMS}

ATR

AW

BEA

CFA

DEQ

DOE-HQ

DOE-ID

EAL

EAM

ECC

ED

EM

EMS

ENS

EOC

ERO

FAEDC

FD

IAP

IC

INL

INTEC

IST

JIC

MFC
Advanced Test Reactor

area wardens

Battelle Energy Alliance, LLC

Central Facilities Area

Department of Environmental Quality

Department of Energy Headquarters

Department of Energy Idaho Operations Office

emergency action level

emergency action manager

emergency control center

emergency director

emergency management

emergency medical services

emergency notification system

emergency operations center

emergency response organization

Fire Alarm Emergency and Dispatch Center

Fire Department

incident action plan

incident commander

Idaho National Laboratory

Idaho Nuclear Technology and Engineering Center

Issues Screening Team

Joint Information Center

Materials and Fuels Complex 


\begin{tabular}{ll} 
NOK & next-of-kin \\
NRC & Nuclear Regulatory Commission \\
NRF & Naval Reactors Facility \\
OE & operational emergency \\
ORPS & Occurrence Reporting and Processing System \\
PA & protective actions \\
PAL & personnel accountability leader \\
PAR & protective action recommendations \\
PID & public information director \\
RWMC & Radioactive Waste Management Complex \\
SAE & site area emergency \\
SMC & Specific Manufacturing Capability \\
SMT & site monitoring team \\
SMTC & site monitoring team coordinator \\
SO & systems operational \\
SS & shift supervisor \\
WCC & Warning Communications Center \\
\hline
\end{tabular}




\section{After Action Report: \\ Idaho National Laboratory \\ 2017 Annual Exercise \\ September 20, 2017}

\section{PURPOSE}

The purpose of this report is to document the results of the 2017 annual exercise conducted on September 20, 2017 at the Idaho National Laboratory (INL). This exercise was conducted in coordination with other INL contractors and applicable local jurisdictions, Department of Energy Idaho Operations Office (DOE-ID), and DOE Headquarters (DOE-HQ). The INL management and operating contractor, Battelle Energy Alliance, LLC (BEA) conducted the annual emergency exercise to demonstrate appropriate response measures to mitigate an event and protect the health and safety of personnel, the environment, and property. Offsite response organizations participated in the notification process to demonstrate appropriate response measures.

This exercise evaluation serves as a management assessment of the performance for the INL Emergency Management (EM) Program.

\section{SCOPE}

Participants and their extent of play are shown in Table 1.

Table 1. Participants and extent of play.

$\underline{\text { Participants }}$

Extent of Play

INL Emergency Response Organizations (EROs)

Advanced Test Reactor (ATR) Complex

N/A

Central Facilities Area (CFA)

Full participation

Idaho Nuclear Technology and Engineering Center (INTEC)

Control Cell

Emergency Operations Center (EOC)

Full participation

Materials and Fuels Complex (MFC)

N/A

Naval Reactors Facility (NRF)

$\mathrm{N} / \mathrm{A}$

Radioactive Waste Management Complex (RWMC)

N/A

Specific Manufacturing Capability (SMC)

Full participation

\section{$\underline{\text { INL Organizations/Elements }}$}

Fire Alarm and Emergency Dispatch Center (FAEDC)

Full participation

INL Fire Department (FD)

Full participation

Initiating Facility Operations Personnel (Operations Drill)

Full participation

Joint Information Center (JIC)

Full participation

Occupational Medicine

Full participation

Packaging and Transportation

N/A

Security

Full participation 
Table 1. (continued).

\begin{tabular}{ll}
\multicolumn{1}{c}{ Participants } & $\underline{\text { Extent of Play }}$ \\
Site Monitoring Team (SMT) & Full participation \\
Transportation \& Fleet Management (Bus Operations) & N/A \\
Warning Communications Center (WCC) & Full participation \\
& \\
\hline Contiguous Counties & \\
Bingham & Notifications Only \\
Bonneville & Notifications Only \\
Butte & Notifications Only \\
Clark & Notifications Only \\
Jefferson & Notifications Only
\end{tabular}

Federal Agencies

Department of Energy Headquarters (DOE-HQ)

Notifications Only

Department of Energy Idaho Operations Office (DOE-ID)

Full participation

Nuclear Regulatory Commission (NRC)

N/A

$\underline{\text { State of Idaho Agencies }}$

Idaho State Communications Center

Notifications Only

Idaho State Police District 6

Notifications Only

Idaho Radiation Control Program

$\mathrm{N} / \mathrm{A}$

INL Department of Environmental Quality (DEQ) Oversight

Full participation

Program

Tribal Authority

Shoshone/Bannock Tribe

Notifications Only 


\section{EXERCISE SUMMARY}

\section{Background}

SMC processes were functioning as designed. It was simulated that SMC operations personnel were performing a systems operational (SO) test on Boiler "B". Various indications of erratic boiler operations were presented to the SMC operator by the controller and discussed. At the conclusion of those discussions, the operator was told by the controller that none of the corrective actions had corrected the problem.

\section{Exercise Start}

It was simulated that during testing of Boiler "B" located in building TAN-679, the shut-off for the pilot oil nozzle failed to close fully when the boiler cycled off. Oil flooded the main flame tube and when the boiler cycled on purge cycle, it was not adequate to clear all of the fuel from the chamber. The remaining atomized fuel in the chamber exploded causing an over pressurization of the boiler. As the pressure rapidly increased, the brass bolts on the east end of the boiler failed allowing the end to sheer off as steam rapidly released into the room. The end cap was launched through the east wall breaking several other pieces of equipment in its path allowing them to become projectiles. The end cap traveled across the alley way and came to rest next to building TAN-629. Several objects were projected through the north roll up door and wall, removing several pieces of the wall covering leaving the room exposed. Fire water lines were broken causing firewater to dump into the room and activate water flow alarms. Fire alarms were simulated as being activated from TAN-679 by Life Safety personnel placing the alarm in test mode and tripping two water flow alarms that sent signals to the Fire Alarm and Emergency Dispatch Center (FAEDC) indicating that water flow fire alarms had activated, thereby initiating the INL FD response. It was simulated that the audible alarms and strobe lights were activated, as was the evacuation of the applicable buildings. Upon hearing that the FD was dispatched, applicable announcements were made by SMC security personnel from TAN-676 (SMC Guard House) using the emergency notification system (ENS). The SMC shift supervisor (SS) and the SMC emergency action manager (EAM) responded to the event area.

The boiler operator followed applicable procedures and processes by contacting the FAEDC using the designated emergency call number "777". He reported there had been an explosion and two personnel were missing. This information was relayed to first responders that were en route. He then reported to the event area and briefed the SS and the EAM, along with the incident commander (IC), when they arrived.

Parked north of the boiler room was a tractor-trailer rig in the process of delivering diesel fuel to the underground storage tanks. The tanker, truck driver, and one other individual were struck by small pieces of debris. The driver and escort were injured and the tanker began leaking diesel fuel on the ground as well. The driver and the escort extricated themselves to a safe location.

FD personnel from Station 3 arrived, picked up the SMC nurse, and promptly established their incident command post, began scene size-up, and treatment of the truck driver and escort. SMC security personnel established contact with the IC, implemented access control measures, and communications with INL security.

The SMC EAM activated the SMC ERO by voice announcement using the facility ENS, notified the WCC of the SMC ERO activation, and requested WCC to activate the SMC ERO team via the INL ENS. The WCC operator notified the support director who requested a conference call be established with the emergency director (ED) and the CFA EAM. A briefing on the event was held and a decision to activate the EOC, JIC, and the CFA emergency control center (ECC) was made. WCC personnel effectively activated the EOC, JIC, and the CFA ECC using the INL ENS. 
Inside the boiler room, it was simulated that the building fire water lines and the diesel fuel lines for the boilers were broken, allowing diesel fuel to run into the pit area. The diesel fuel in the pit ignited on fire. Near the pit were two 55-gallon drums, one of which is a boiler treatment chemical, AMERCOR 8548. This drum was heated by the fire, which increased the vapor pressure within the drum causing the drum to vent violently releasing material that also ignited. The drum was propelled through the opening in the wall spilling the remainder of the 55 gallons of fuel onto the ground next to the tanker and on the leaking diesel fuel. The diesel fuel around the tanker caught on fire and began impinging upon the tanker.

The IC determined an incident action plan (IAP) and successfully implemented it. FD emergency medical services (EMS) personnel and the SMC nurse treated the two injured personnel and simulated transport to the CFA medical facility. FD personnel effectively deployed the master stream device by charging fire hoses and momentarily spraying water near the tanker to simulate application to the tanker fire and the building fire.

Based on the initial information that the event was a fire and explosion, emergency action levels (EALs) for both event types were reviewed. The SMC EAM initially categorized the event as an unclassified operational emergency (OE) at 1316 using two EALs, both of which were applicable. One for the explosion, SMC-ALL-2.OE.1; and one for the fire, SMC-ALL-A.OE.1. The declaration was within the 15-minute time requirement for declaration. The notifications form was completed using the electronic process contained within WebEOC. Once it was approved by the SMC EAM, it was submitted to the WCC by the SMC notification specialist. Initially, WCC personnel had some difficulty in locating, downloading, and printing the notification form. To expedite the process, the SMC notification specialist faxed the WCC a copy so offsite notifications could be completed. The WCC transmitted the initial offsite notification to offsite participants and completed the offsite notification process at 1350. All follow-up offsite notifications were filled out, submitted to the WCC, and then simulated as being transmitted to the offsite agencies except the termination notification, which was transmitted to the offsite agencies.

Initial protective actions (PAs) were reviewed. Implementation of PAs and protective action recommendations (PARs) were simulated. CFA ECC personnel made notifications to field workers. Accountability of non-essential personnel within the event area was completed using established procedures and processes. Any additional resources were simulated as responding, if requested.

As the event progressed, FD personnel reported that the drum involved in the fire contained a corrosive, but they could not get any closer to identify the product by name. Based on the available information, the SMC EAM assumed a worst-case scenario that the drum contained the AMERCOR product. Using this new information, additional EALs were reviewed for consideration in the categorization/classification process. It was accurately determined that a site area emergency (SAE) had been reached. The EAM immediately implemented the protective actions for the SAE, waited for the initial notifications to be completed, and then upgraded the event to a SAE in accordance with applicable procedures and time requirements.

As utilities to the building were requested to be isolated, it was simulated so normal facility operations were not directly impacted.

The SMC ECC, EOC, JIC, and CFA ECC were declared operational as staffing levels were achieved.

INL EOC consequence assessment specialists received consequence assessment forms along with verbal information from SMC, which allowed them to effectively review applicable information and verify protective actions were adequate and that the correct EAL(s) had been identified. 
Effective command bridge briefings occurred throughout the event. Categorization/classification and notifications responsibilities were transferred to the ED per applicable procedures. The SMC EAM determined to maintain responsibilities for PAs for SMC.

The INL HAZMAT team responded to the event area and effectively determined how to contain the spill. Actual containment was simulated. They effectively worked under the direction and control of the IC during mitigation activities. Sand and a backhoe were requested through the SMC ECC to be applied to the spill to adsorb the spill material. This request was successfully coordinated with CFA ECC personnel who arranged for the sand. SMC determined they had access to a backhoe and a front-end loader located at SMC.

Environmental issues were addressed and environmental notifications made.

During the search of the affected area by FD personnel, two persons inside the boiler room were located, one of which was severely injured. It was determined that the other was deceased and was left in the area. Actual next-of-kin (NOK) notifications were simulated.

It was determined that reentry would not be attempted. A recovery manager was appointed and responded to the SMC ECC for a briefing. He began recovery planning per the applicable procedure.

Once the leak was stopped, the spill area contained by diking the area and applying an absorbent material, the fires declared out, search and rescue efforts complete, and scene preservation established, the FD returned control of the event area back to SMC facility personnel.

The exercise director contacted each lead controller to verify that all objectives have been sufficiently attempted and obtained concurrence for termination of the exercise. When verification was obtained, the exercise was terminated, exercise windows closed, and hot wash critiques held. The WCC received a termination notification form, transmitted it to participating agencies, and made applicable announcements to close the exercise window. 


\section{DRILL OBJECTIVES AND EVALUATION}

During the exercise, all 16 standardized INL objectives were evaluated using the appropriate demonstration criteria. All objectives were rated satisfactory or satisfactory with improvement needed.

The ratings in Table 2 are based on the issues that follow in Section 5 of this report.

Table 2. Evaluation matrix.

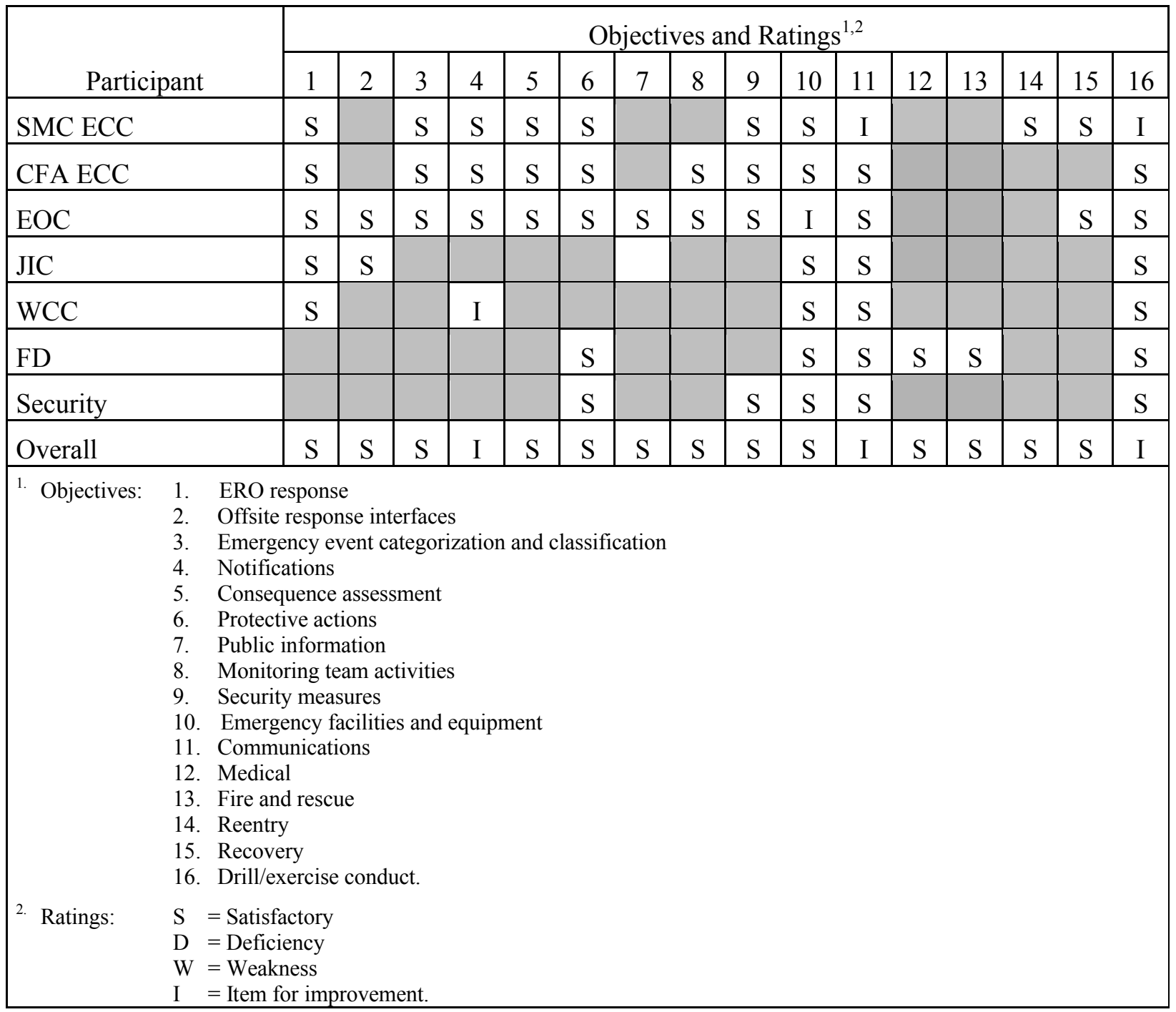




\section{DRILL ISSUES}

The following issues are specific to the evaluation of SMC, CFA ECC, EOC, JIC, and associated response elements. Each item has been evaluated and entered into the appropriate issues management system.

\subsection{Emergency Response Organization Response}

Given the facility procedures/plan, the ERO will respond to, monitor, and evaluate the specific indicators of an emergency for mitigation of the consequences and bring the emergency situation under control.

Objective Demonstrated: Yes $\quad \begin{array}{llll}\text { No } & \square & \text { N/A }\end{array}$

\section{Discussion}

All EAMs and the ED received event information and followed applicable procedures and processes to activate their respective ERO teams including the JIC. The process for activation was followed and equipment functioned as designed. ERO personnel responded to their duty stations quickly, which enabled each to be declared operational in a timely manner. ERO response personnel utilized their applicable procedures, checklists, and logs to perform their functions.

Communication channels were established between the ERO response elements, which provided for transmittal of information between emergency facilities. As information became available, briefings were provided to ERO personnel. Assignments and tasks were clear and made to the appropriate personnel. Overall, ERO staff successfully demonstrated their knowledge and use of response resources, capabilities, and how to access and use them. Support personnel were able to obtain and analyze the necessary information to support the ERO.

Overall, the designated personnel successfully demonstrated direction and control of the response effort by establishing priorities and making task assignments while maintaining safety. Facility EAMs and the ED were able to demonstrate their knowledge of the resources available to them, which allowed for the mitigation of the event. Briefings were conducted with ERO personnel and the ED kept INL senior management apprised of the event.

It is noted that at SMC, the EAM was not as aggressive in his decision-making and relied on another qualified SMC EAM to maintain his position checklist and remind him of tasks needing to be completed. The designated SMC EAM effectively utilized this assistant to complete tasks, such as making environmental notification, keeping a status board updated, and reminding him of command bridge conference calls. The difference in personalities was evident in that the designated EAM was more quiet and thoughtful in his decision making, while the assistant demonstrated a stronger presence. The assistant EAM appeared to recognize this and was very effective in only recommending actions or suggesting to the EAM things to consider in his decision-making. At no time did the assistant ever take command or control of the event mitigation activities. It was evident who the EAM was and that he was in charge throughout the exercise.

Issue No issues were found with the performance of this activity.

\subsection{Offsite Response Interfaces}

Given the facility procedures/plan, the ERO will coordinate and interface with response organizations to protect the environment and health and safety of the public.

$$
\text { Objective Demonstrated: Yes } \quad \text { } \quad \text { No } \quad \square \quad \text { N/A }
$$

\section{$\underline{\text { Discussion }}$}


An effective interface was coordinated with Federal, state, tribal, and local agencies and organizations responsible for offsite emergency response was demonstrated. Initial event notifications were provided to local offsite agencies using established procedures and practices. Emergency facility equipment functioned to allow written and verbal communications among the various agencies. Follow-up notifications were simulated to local and offsite agencies. Within the EOC, there was excellent interaction and communication between EOC ERO members and INL State of Idaho DEQ oversight personnel.

Issues No issues were found with the performance of this activity.

\subsection{Emergency Event Categorization and Classification}

Given the facility procedures/plan, the ERO will accurately and promptly categorize and classify the operational emergency.

\section{Objective Demonstrated: Yes $\quad$ $\quad$ No $\quad \square \quad$ N/A}

\section{Discussion}

The SMC EAM and supporting ERO staff accurately and promptly categorized the event as an unclassified $\mathrm{OE}$ at 1316 hours. This was accomplished in accordance with facility procedures and within the time requirements from event recognition. As the event progressed, it was determined that a corrosive material had been released. Though the actual content of the drum was not determined, the EAM utilized his familiarity of the boiler plant and what chemicals were used to assume it was the AMERCOR product, which is the most hazardous material they use. Based on this knowledge, he classified the event as a SAE using the correct EAL.

Categorization/classification of the event was effectively transferred to the ED following applicable procedures and processes.

Issues No issues were found with the performance of this activity.

\subsection{Notifications}

Given the facility procedures/plan, the ERO will report emergencies and conduct follow-up notifications to the appropriate organizations within the required time.

Objective Demonstrated: Yes $\quad$ No $\quad \square \quad$ N/A

\section{$\underline{\text { Discussion }}$}

At 1316, the event was categorized as an OE. The SMC notification specialist submitted the electronic notification form to the WCC using WebEOC at 1325. The SMC notification specialist contacted the WCC to verify receipt of the form. WCC personnel were unable to retrieve the form using WebEOC and asked for a faxed copy or an emailed version. The SMC notification specialist had difficulty in getting the initial notification form printed. Once printed, the form was faxed to the WCC at 1337. It appears that the WCC received it at 1340 and completed the initial offsite notification at 1350 , which is 4 minutes past the time for an unclassified $\mathrm{OE}$.

Follow-up notifications were subsequently completed within the time requirements as event conditions changed and classification/reclassification of the event occurred. A termination notification was completed.

A review of the notification forms submitted indicated a few errors. The time that the SAE was declared was omitted form the follow-up notification form as was the time of notification.

Issue 5.4.1 Initial offsite notifications for an unclassified OE were not completed within the 30-minute time requirement. A review of the exercise documents indicates there were a couple of causes that contributed to missing the 30-minute time requirement. First, the WCC could not locate the initial 
notification form contained in WebEOC when it was submitted. This caused the SMC notification specialist to have to print the form and fax it to the WCC. A review of the training records in the INL TRAIN system indicates the WCC personnel may not have had the necessary training associated with the notification process using WebEOC. If it was conducted, it was not documented. Second, during conversations after the exercise, there appears to be some confusion within the WCC as to what time is considered the "time of notification" that needs to be documented. Third, the SMC notification specialist had difficulty in linking the CPU to a local printer. The default printer has been identified and this part of the issue has since been corrected.

Action 5.4.1.1 $\quad \square$ Deficiency $\square$ Weakness $\quad \square$ Item for Improvement $\square$ Track \& Trend

Action statement: Provide all WCC personnel training on the use of the WebEOC software for receiving and completing emergency notification forms; the importance of documenting the time of notifications, including what time is considered the "time of notification"; and how to transmit them to offsite agencies and onsite organizations. Laboratory Protection LabWay \#LP-CO 2017-0643 assigned.

Action 5.4.1.2 $\quad \square$ Deficiency $\square$ Weakness $\quad \square$ Item for Improvement $\square$ Track \& Trend

Action statement: EM personnel will review the requirements for verbal notifications and/or written notification for offsite agencies. Consider the current use of WebEOC and Everbridge capabilities, make a recommendation to the EM Issues Screen Team (IST) as to when we determine the time of notifications. Currently it is when the WCC operator, or whoever, is making the notification begins to read the form. Laboratory Protection LabWay \#LP-CO 2017-0645 assigned.

\subsection{Consequence Assessment}

Given the facility procedures/plan, the ERO will assess actual and potential onsite and offsite consequences of an emergency.

Objective Demonstrated: Yes $\quad$ No $\quad \square \quad$ N/A

\section{$\underline{\text { Discussion }}$}

Initial and on-going consequence assessment was successfully demonstrated by using default assessment data and then continuing to monitor the event and update as new information was received.

Default information was used in conjunction with meteorological information to verify initial PA distances were adequate. EALs were verified using event information provided from SMC ERO personnel. Consequence assessment forms were completed and submitted to the EOC consequence assessment team to document event conditions from SMC. As additional event information was received, consequence assessment personnel continued to monitor the event and provide recommendations to ERO personnel. There were equipment problems that will be addressed elsewhere in this document.

Meteorological information was available, utilized throughout the exercise, and used in the consequence assessment process including weather forecast capabilities.

Overall, this objective was successfully demonstrated with the performance of the consequence assessment process and updates provided to the appropriate decision-makers.

Issues No issues were found with the performance of this activity. 


\subsection{Protective Actions}

Given the facility procedures/plan, the ERO will respond to emergency conditions to protect onsite personnel and the public by implementing specific, predetermined actions.

\section{Objective Demonstrated: Yes $\quad$ N No $\quad \square \quad$ N/A}

\section{Discussion}

Though the implementation of PAs and PARs was simulated, the SMC EAM used the applicable EAL to determine the correct PAs/PARs. As the event progressed and additional hazards were identified, PAs were reviewed and modified correctly.

The term "accountability complete" is still confusing to some personnel. The IC was told that accountability was complete; meaning the area wardens (AWs) had swept their areas and reported to the IC what areas had not been swept or cleared. In this exercise, the person representing the AW told the IC which areas had not been swept. This provided the IC with some direction for searching for the missing personnel. When the term "accountability complete" was used in the SMC ECC, some personnel thought that meant everyone was accounted for by name. At this time in the exercise, there was still some confusion on how many were injured and how many, if any, were missing. Once it was determined to evacuate all personnel to the SMC cafeteria, the personnel accountability leader (PAL) was able to use the Argus system to identify by name who was still missing. The information matched with the injured personnel. This same issue was identified in the drill conducted at SMC on July 12, 2017, and is being addressed by a corrective action being tracked in LabWay to clarify accountability terminology and bring results to IST for further actions, if necessary. (See Laboratory Protection LabWay \#LP-CO 2017-0425)

Issues No issues were found with the performance of this activity.

\subsection{Public Information}

Given the facility procedures/plan, the ERO will demonstrate an emergency public information program.

Objective Demonstrated: Yes $\quad$ No $\quad \square \quad$ N/A

\section{$\underline{\text { Discussion }}$}

The JIC was activated in conjunction with the EOC and declared operational in a timely manner.

News releases were developed by the public information director, approved by the applicable personnel within the EOC, and distributed to the JIC for dissemination. Actors portraying family members, employees, and media outlets called the JIC and asked various questions, which were handled in a professional and appropriate manner. Social and news media outlets were successfully monitored for rumor control and clarification.

Issues No issues were found with the performance of this activity.

\subsection{Monitoring Team Activities}

Given the facility procedures/plan, the ERO will provide facility/site monitoring teams in support of consequence assessment activities.

Objective Demonstrated: Yes $\quad$ No $\quad \square \quad$ N/A

\section{$\underline{\text { Discussion }}$}

The INL site monitoring team (SMT) was successfully deployed for this exercise even though there was not a radiological release. Equipment checks were completed per procedure and applicable direction and control given by the site monitoring team coordinator (SMTC). They successfully coordinated with 
the SMTC and the EOC consequence assessment team to verify that a radiological release had not occurred. Applicable procedures, forms, and checklists were utilized. It is noted here that in the interest of time and safety, the SMT was deployed to an area close to the CFA ECC rather than have them drive the 30-plus-minutes to SMC through a road construction zone, which caused significant delays in travel times.

Issues No issues were found with the performance of this activity.

\subsection{Security Measures}

Given the facility procedures/plan, Security will respond to, monitor, and evaluate the specific indicators of an emergency for mitigation of the consequences and bring the emergency situation under control.

Objective Demonstrated: Yes $\quad$ No $\quad \square \quad$ N/A

\section{$\underline{\text { Discussion }}$}

INL Security personnel followed applicable procedures to mobilize appropriate security response personnel. A unified command was established with INL FD personnel. They quickly established access control to the affected areas and strictly controlled access to the event area throughout the exercise.

Security consulted appropriate emergency response resources for initial event information.

An effective communications network was utilized between security responders and IC to ensure the safety of personnel and the protection of assets involved in the event.

Security personnel assigned in the CFA ECC and EOC effectively demonstrated their response actions including establishing communications network with each other and the shift captain and SMC security personnel.

Issues No issues were found with the performance of this activity.

\subsection{Emergency Facilities and Equipment}

Demonstrate the adequacy of facilities, equipment, displays, and other materials to support emergency operations.

Objective Demonstrated: Yes $\quad$ No $\quad \square \quad$ N/A

\section{Discussion}

Facilities and equipment were used effectively during the exercise to support emergency response operations. Equipment used in the INL WCC to facilitate response activities, including the use of the Everbridge System to activate the INL ERO elements, functioned properly. Facilities and equipment were available and are adequate to support emergency response activities. Responders were able to find the supporting references and materials to support their activities except as noted below.

ERO personnel demonstrated a noteworthy use of their procedures, checklists, and peer-checking during the exercise.

At SMC, the radio used by the SMC SS to communicate with the ECC did not work. ERO personnel used a runner to relay information between the scene and the ECC until a second radio was located and used. In addition, there was a problem trying to fax the consequence assessment form to the EOC. Three (3) different phone numbers were tried until personnel were successful in transmitting the form.

INL JIC equipment functioned throughout the exercise. Resources were easily accessible and JIC personnel utilized them as appropriate. Facilities and equipment were adequate for response in the INL EOC Public Information area. 
FD, EMS, and Security personnel effectively utilized their equipment, procedures, and processes to effectively respond to and mitigate the identified hazards during this exercise. No issues with their equipment were identified.

Overall, the equipment utilized for this exercise worked as designed and provided for a coordinated response to the event. All of the facilities infrastructure equipment, such as lighting and ventilation, functioned properly and adequately supported the response activities.

Overall, this objective was successfully demonstrated with opportunities for improvement as noted below.

Issue 5.10.1 During the 2017 annual ERO exercise, three (3) different fax numbers were used when trying to transmit the consequence assessment form to the EOC. One (1) of these numbers is the phone number listed on the consequence assessment form.

Action 5.10.1 $\square$ Deficiency $\square$ Weakness $\square$ Item for Improvement $\square$ Track \& Trend

Action statement: EOC emergency planner will determine if the phone number for transmitting the consequence assessment form is correctly identified on the form; if the current fax machine is adequate, or if the new combination copier/fax machine should be utilized; or if an electronic process such as WebEOC should be used and make recommendations to the EM IST. Laboratory Protection LabWay \#LP-CO 2017-0646 assigned.

\subsection{Communications}

Communications capabilities are managed in support of emergency operations to ensure prompt and appropriate flow of accurate information during an emergency.

\section{Objective Demonstrated: Yes $\quad$ No $\quad \square \quad$ N/A}

\section{Discussion}

Communications within the ECCs and the EOC were effective. Repeat-backs or 3-way communications were used during the exercise throughout most of the exercise. Personnel at the scene did an excellent job in demonstrating 3-way communications between response elements and with the SMC ECC. Personnel in the EOC and CFA ECC wore their applicable vests and addressed each other by titles. There were occasional lapses within the SMC ECC in using repeat-backs. Personnel using radio communications and on the various conference bridges effectively called personnel by their respective position titles, but there was a noted lack of identifying ERO members by their respective position titles when speaking face-to-face in the SMC ECC. This may be an inherent problem since the SMC ERO members work day-to-day with each other in a small facility with a small population, so by default, it would be expected that they call each other by their personal name(s). For example, in the SMC ECC, the EAM put on his vest and activated his position; as ERO members arrived, the SMC EAM would ask each of them by name what position they were filling and they would respond, so he knew who was filling each position, even though two of the five did not wear their position vests. Though this is not the preferred method of communication, in a small team like SMC where there are only five identified ERO positions, they are able to function effectively calling each other by name when only the on-duty team is in the ECC. This becomes somewhat confusing when additional personnel come in such as an assistant EAM or a scribe who does not have a vest to wear that identifies him/her by position. When these individuals start contributing event information, it can become confusing to ERO members and observers as to who is functioning in what capacity. Combined together, the personnel not wearing vests and not identifying ERO members by positon, it was sometimes confusing as to who was functioning in what position or what their responsibilities were within the SMC ECC. 
Effective command and control was demonstrated throughout the exercise. This was evident at the scene as demonstrated by the first responders who established incident command and provided direction and control for responders. The FD captain completed a scene size-up utilizing applicable resources and provided direction to his crew, which led to an effective response to treat the injured, mitigate the hazards, and complete search and rescue activities. Communications were established between the scene and the SMC ECC. SMC security personnel responded with the FD and worked with the IC in establishing access control. When the battalion chief arrived, a successful turnover occurred. Effective communications between the incident scene and the SMC ECC continued throughout the exercise. When equipment problems occurred, response personnel utilized pre-identified alternate communication methods until a replacement radio was found. One area were improvement could occur is in use of terminology. For example, responders use terms such as "one-black" or "one-red" in reference to injured personnel. Some ERO members were not sure what those terms mean. INL EM is currently developing training and associated training to clear up this confusion.

Effective communications were established between SMC security personnel, CFA security personnel, and the CFA ECC and EOC. Each responder demonstrated effective use of repeat-backs. Communication pathways were recognized and utilized to respond to this event.

Overall, ERO personnel demonstrated effective command and control during the exercise within their areas of responsibility as demonstrated during briefings conducted by the applicable EAMs within the ECCs and by the ED in the EOC. Assignments were made and carried out. As the exercise wore on, the SMC EAM needed to conduct briefings that were more frequent so the entire team could be informed at the same time. He did an effective job of keeping the two or three people right around him up-to-date. However, personnel working further away, such as the PAL and the planning communicator, missed some of the information.

Communications between the INL ECCs, including INTEC, and the EOC were established and utilized throughout the exercise. Information was passed across the planning bridge between all participating ECCs with event briefings being conducted over the command bridge involving all EAMs and the ED.

INL WCC emergency reporting equipment worked to effectively notify offsite agencies of the event and applicable PARs. WCC personnel effectively handled calls and alarms per applicable procedures and protocols.

Within the Public Affairs area in the EOC, personnel consistently communicated with INL JIC personnel and the INL public information director (PID). Relevant information was shared between the INL EOC and JIC. JIC team members demonstrated how to use emergency communications protocols during drills, exercises, and actual events.

Communication systems were utilized and worked as designed to provide prompt and reliable communications to ERO team members and non-essential personnel during the exercise.

Issue 5.11.1 During the 2017 annual ERO exercise, communications within the SMC ECC were not as effective as they could have been. First, the ERO team did not effectively use repeat-backs or three-way communications when speaking face-to-face. Second, team members were not easily identifiable in that they did not address each other by position title. Finally, of the five designated ERO members, only three wore their vests to identify them by their position.

\section{Action 5.11.1 $\quad \square$ Deficiency $\square$ Weakness $\quad \square$ Item for Improvement $\square$ Track \& Trend}

Action statement: Issue a lessons learned to all ERO personnel that includes a reminder to use repeat-backs when addressing other ERO members face-to-face and second to identify each other by position title when addressing each other. Third, wear applicable position vests when responding to an event, exercise, or drill. Laboratory Protection LabWay \#LP-CO 2017-0647 assigned. 


\title{
5.12 Medical
}

Given the facility procedures/plan, medical response personnel will respond to, monitor, and evaluate the specific indicators of an emergency for mitigation of the consequences and bring the emergency situation under control.

\begin{abstract}
Objective Demonstrated: Yes $\quad \begin{array}{llll}\text { No } & \square & \text { N/A }\end{array}$

\section{Discussion}

EMS personnel carried out their applicable activities in a coordinated and safe manner. The ambulance crew picked up the SMC nurse during their initial response. They surveyed the scene for safety hazards prior to entry and established a protective zone around injured personnel by ensuring they were treated in a safe area away from the hazards. EMS personnel effectively determined the nature and extent of the injuries and simulated applicable treatment.
\end{abstract}

Though actual transport of the injured was simulated, the injured were packaged and loaded into an ambulance in preparation of being transported to the CFA medical facility. The ambulance crew communicated operational status to the FAEDC and the IC.

Issues No issues were found with the performance of this activity.

\subsection{Fire and Rescue}

Given the procedures/plan, fire and rescue responders will respond to an event involving fire or hazardous material, mitigate the consequences, and bring the situation under control.

\section{Objective Demonstrated: Yes $\quad$ V No $\quad \square \quad$ N/A}

\section{$\underline{\text { Discussion }}$}

INL FD personnel and equipment were deployed to the scene in a timely manner. Responders initiated an effective response that led to timely mitigation of the event conditions. Incident command was established, an initial scene size-up performed, traffic and personnel access control established, and necessary precautions were taken for contamination, exposure to hazardous material, heat, and personal safety. The IC determined and obtained additional resources, as appropriate, to respond to the incident/accident. Communications links used by responders handled all necessary traffic.

About 25 minutes into the exercise, the battalion chief arrived and assumed IC responsibilities. The IC demonstrated a leadership role by providing instructions to staff on response operations, decisionmaking, and coordination of response activities. The IC established and maintained the overall responsibility for the awareness of the location (accountability) of responders at the emergency scene. He established and maintained communications with all response organizations supporting on-scene response. The communications network established between the IC and all on-scene responders was adequate to support safe and effective response operation.

FD personnel conducted rescue operations, as appropriate, using established procedures, completed activities to extinguish the fire simulated in the boiler room and on the tractor/trailer. HAZMAT personnel effectively demonstrated how to control the spill through a series of demonstrations, simulations, and discussions. FD personnel demonstrated the safe and proper use of equipment.

Issues No issues were found with the performance of this activity. 


\title{
5.14 Reentry
}

The ERO will demonstrate development and implementation of a reentry plan to include debriefing of the reentry team and proper recordkeeping in accordance with the facility procedures/plan.

\section{Objective Demonstrated: Yes $\quad \begin{array}{llll}\text { No } & \square & \text { N/A }\end{array}$}

\section{$\underline{\text { Discussion }}$}

For this exercise, the SMC ERO team reviewed the need for reentry and made a determination based on exercise events, hazards, and facility damage and determined not to conduct a reentry. It was determined that all activities would be conducted under recovery operations.

Issues No issues were found with the performance of this activity.

\subsection{Recovery}

Given the facility procedures/plan, the ERO will demonstrate recovery planning for an emergency at the affected facility.

\begin{abstract}
Objective Demonstrated: Yes $\quad \begin{array}{llll}\text { No } & \square & \text { N/A }\end{array}$
$\underline{\text { Discussion }}$

For this exercise, a recovery manager was identified. The recovery manager responded to the SMC ECC where he was briefed on the event. He utilized the applicable procedure and initiated a recovery plan, which included identifying the initial actions and identifying recovery team members.
\end{abstract}

Issues No issues were found with the performance of this activity.

\subsection{Drill/Exercise Conduct}

Write, conduct, and evaluate a drill/exercise that will emphasize facility-specific emergency events and response activities and minimize the use of generic, nonspecific simulations in accordance with the facility procedures/plan.

Objective Demonstrated: Yes $\quad$ N $\quad$ No $\quad \square \quad$ N/A

\section{Discussion}

A technically accurate, emergency event scenario with clear measurable objectives was presented and responded to by facility ERO teams and response organizations. The scenario emphasized a challenging series of emergency events with provisions for realistic free-play during response actions. Event data and information presented during the exercise provided the sequence of the events in a realistic manner and was representative of actual facility conditions. During the conduct of the drill, opportunities for improvement were identified and are documented in other applicable sections.

Controllers were utilized to facilitate performance of the players and ensure safe and effective conduct of the exercise. Cue cards were well written, provided applicable relevant information on the initiating event and follow-up event to keep the exercise moving in the right direction and at the correct times, and kept to a minimum.

During the exercise, the notification specialist submitted the notification form to the WCC using WebEOC. However, WCC personnel stated they did not received the form, causing the SMC notification specialist to think she had done something incorrectly. She went to the SMC lead controller and explained the problem. The SMC lead controller inadvertently provided direction to the notification specialist by asking if they had pushed the submit button and the print button instead of asking a more generic question such as "what actions had she done." Even though the notification specialist responded affirmatively to the questions she was asked, asking those specific questions could have lead the notifications specialist to 
perform a task or action she had not yet completed. There were several times when the SMC EAM or assistant EAM came to the SMC lead controller to ask for clarification on whether or not to simulate an action or to preform it. On one occasion, the SMC EAM started down a path for Occurrence Reporting and Processing System (ORPS) reporting and the SMC ECC lead controller stopped the action to prevent ERO personnel from performing actions not required of the ERO. Almost simultaneously, the DOE-ID facility representative stepped in and provided the same information that the lead controller had started to provide.

Exercise controllers and evaluators were briefed and instructed on their assignments prior to the exercise. Exercise conduct evidenced much preparation and training. Controllers and evaluators were jointly involved in the pre-exercise briefings. There were a sufficient number of controllers and evaluators to provide coverage for all participating areas.

Evaluators were utilized to observe, evaluate, and critique performance of the exercise. After the termination of the exercise, "hot wash" critiques were conducted with all exercise participants immediately following termination of the exercise at each of the evaluated areas. Evaluators and controllers discussed exercise performance and each of the objectives.

Issue 5.16.1 The SMC ECC lead controller asking poorly phrased questions when the notification specialist asked for assistance during the notification process, which could have provided direction and/or help during the 2017 exercise. During the exercise, the notification specialist had submitted the notification form to the WCC using WebEOC. However, WCC personnel stated they did not received the form, causing the SMC notification specialist to think she had done something incorrectly. The SMC lead controller inadvertently provided direction to the notification specialist by asking if they had completed a specific task instead of asking what actions she had done. Even though the notification specialist responded affirmatively to the questions she was asked, asking pointed questions would have lead the notifications specialist to complete a task or action she had not yet completed.

Action 5.16.1 $\square$ Deficiency $\square$ Weakness $\quad \square$ Item for Improvement $\square$ Track \& Trend

Action statement: Send lessons learned to EM personnel emphasizing the importance of not coaching and/or directing response personnel during exercises or evaluated drills by asking leading questions.

Laboratory Protection LabWay \#LP-CO 2016-0648 assigned. 


\section{CONCLUSIONS}

Overall, a successful evaluated exercise was conducted at INL. Of the 16 objectives evaluated, 13 were rated as satisfactory and three were rated as satisfactory with improvements needed. The participating EROs were activated and responded to their duty stations in a timely and effective manner. They utilized applicable procedures and checklists to efficiently and effectively respond to and mitigate the event. The ECCs, EOC, and JIC were declared operational when staffing levels were met. The SMC EAM correctly identified the applicable EAL and declared an OE within the time requirements. Notification forms were submitted to the WCC and offsite notifications were completed, but exceeded the required time-limit for initial notification by approximately four minutes. Categorization/classification, notifications, and protective actions/protective action recommendations functions were successfully transferred to the ED. As event conditions changed, updates were provided and the classification upgraded as new EALs were met. Good communications were demonstrated within and between each of the activated ECCs, the EOC, DOE-ID, and Idaho State Oversite representative. Follow-up offsite notifications were completed in a timely manner and in accordance with applicable procedures.

Protective actions and protective action recommendations were correctly identified with implementation being simulated for this exercise. Pro Force personnel responded and established access control to the event area and the SMC facility.

The SMT was deployed and monitoring data relayed to be utilized in response actions and consequence assessment activities.

Throughout this exercise, ERO personnel were very proactive, thinking ahead, and demonstrating effective communication techniques. It was easy to recognize who was in command and control at each facility with the facility EAMs and the ED effectively coordinating response actions between facilities. They effectively determined what needed to be done to protect personnel, the environment, and equipment in mitigating the event.

Incident command was effectively established and demonstrated throughout this exercise. FD, EMS, and HAZMAT resources demonstrate their response actions safely and effectively. A unified command was successfully demonstrated by FD and security personnel. Traffic and access control was established by SMC security personnel and maintained throughout the exercise. 
INTENTIONALLY LEFT BLANK 
Appendix A

\section{Scenario Narrative}


INTENTIONALLY LEFT BLANK 


\section{Appendix A}

\section{Scenario Narrative}

\section{Background}

INL is a multi-program laboratory owned by the United States government and managed and operated by BEA for DOE-ID. The primary mission of INL is to ensure the nation's energy security with safe, competitive, and sustainable energy systems and unique national and homeland security capabilities. INL works with national and international governments, universities, and industry partners to discover new science and develop technologies underpinning the nation's nuclear and renewable energy, national security, and environmental missions. INL includes BEA-managed and -operated facilities that are located on the desert Site. The Site is an 890-square-mile area of open, sagebrush-covered desert land in southeastern Idaho, approximately 25 miles west of Idaho Falls. Facilities managed and operated by other contractors for DOE-ID are also located on the Site.

SMC, which is located on the INL Site, develops specific manufacturing capabilities as directed by the Department of Defense, and manufactures armor for the U.S. Army. SMC is classified as a DOE Hazard-Category-3 nuclear facility. SMC consists of fabrication and assembly, rolling operations, and support facilities and provides product and recyclable material transportation. Fabrication and assembly facilities contain production areas and space for offices, support functions, and service areas. TAN-679 and TAN-681 operations include areas for process production; shipping, receiving, and storing material; a Radiological Control field office; a maintenance area; a boiler room; administrative offices; and change room facilities. SMC support facilities include a guard post (TAN-676), a cafeteria, and an ECC (TAN678), utilities and offices, a warehouse, and an office complex. Access to SMC is obtained through the TAN-676 Guard House. A medical clinic is located at SMC outside of the fenced perimeter.

SMC processes are functioning as designed. Operations personnel are performing a systems operational test on Boiler "B".

\section{Exercise Start}

During testing of Boiler "B" located in building TAN-679, the shut off for the pilot oil nozzle fails to close fully when the boiler cycles off. Oil floods the main flame tube and when the boiler cycles on purge cycle, it is not adequate to clear all of the fuel from the chamber. The remaining atomized fuel in the chamber explodes, causing an over-pressurization of the boiler. As the pressure rapidly increases, the brass bolts on the east end of the boiler fail allowing the end to sheer off as the steam is rapidly released into the room. The end cap is launched through the east wall breaking several other pieces of equipment in its path, allowing them to also become projectiles. The end cap travels across the alley way and comes to rest next to building TAN-629. Several objects are projected through the north roll up door and wall, removing several pieces of the wall covering leaving the room exposed. Fire water lines are broken causing fire water to dump into the room and activate water flow alarms. Fire alarms will be simulated as being activated from TAN-679 by Life Safety personnel placing the alarm in test mode and tripping two water flow alarms that send a signal to the FAEDC indicating that water flow fire alarms had activated initiating the INL FD response. If actually activated for a real event, this alarm would also activate fire alarms in adjoining buildings TAN-679A and TAN-681, causing an evacuation of all three buildings. Upon hearing that the FD has been dispatched, applicable announcements will be made by SMC security personnel from TAN-676 (SMC Guard House) using the ENS. The SMC SS and the SMC EAM respond to the area. 
Parked north of the Conex containers is a tractor/trailer rig in the process of delivering diesel fuel to the underground storage tanks. The tanker and the truck driver will be struck by small pieces of debris. The driver and escort are therefore injured, and the tanker is leaking diesel fuel on the ground.

In addition to the fire water lines, the diesel fuel lines inside the boiler room are broken, allowing diesel fuel to run into the pit area. The diesel fuel in the pit will ignite on fire. Two 55-gallon drums will be in the vicinity of the pit, one of which is a boiler treatment chemical, AMERCOR 8548, will be heated by the fire. The increase in vapor pressure will cause the drum to vent violently releasing material, which also ignites. The drum is then propelled through the opening in the wall. It clears the Conex container, spilling the remainder of the 55-gallons onto the ground next to the tanker and leaking diesel fuel. The diesel fuel then catches on fire.

Three individuals were evacuating the boiler room at the time of the explosion. Two are struck by debris, one of which is killed. One of the operators who was able to evacuate from the area calls 777 to report the explosion and report that two personnel were with him at the time of the event, but did not come with him out of the building.

The SMC EAM activates the SMC ERO using ENS, notifies the WCC of the SMC ERO activation, and requests WCC to activate the SMC ERO team via the INL ENS as well. The WCC operator notifies the support director who requests a conference call be established with the ED. The ED directs the WCC to activate the EOC, JIC, and the CFA ECC. WCC personnel activate the EOC, JIC, and the CFA ECC.

Initial and ongoing protective actions will be reviewed. Implementation of protective actions and protective action recommendations is simulated. CFA ECC personnel will make notifications to field workers.

Categorization/classification of the event is accomplished and the notifications form sent to the WCC. The WCC transmits the initial offsite notification to offsite participants and completes the offsite notification process. Any follow-up offsite notifications will be simulated.

Accountability of non-essential personnel occurs. Any additional resources will be simulated as responding, if requested.

As the event progresses, additional EALs will be reviewed for inclusion in the categorization/classification process.

FD and EMS personnel will respond and begin initial triage and treatment of the injured personnel. The transportation of injured personnel to offsite medical facilities will be simulated. One individual will be transported to CFA medical.

Applicable utilities to the building/area will be simulated as isolated, if requested.

SMC ECC, EOC, JIC, and the CFA ECC will be declared operational.

INL EOC assessment specialists receive consequence assessment forms, verbal information from $\mathrm{SMC}$, and review applicable information to verify protective actions are adequate and the correct EAL(s) has been identified.

Command bridge briefings occur throughout the event. Categorization/ classification, notifications, and protective action responsibilities will be transferred to the ED per applicable procedures. 
The INL HAZMAT team will respond to assist with the mitigation of the event.

Environmental issues are addressed and environmental notifications made.

During searches of the affected facilities by FD personnel, two persons inside the boiler room are located; one is severely injured, and the other is a deceased boiler operator. The Butte County Coroner is simulated as being contacted. NOK notifications will be performed up to identifying the phone number(s) of the contacts for BEA human resources personnel and/or the truck driver company representative.

Reentry is discussed, and if determined needed, reentry planning will occur, but not be implemented. A recovery manager is appointed and responds to the SMC ECC for a briefing.

The exercise director terminates the exercise when objectives have been met or sufficiently attempted to be met. Emergency facilities are returned to their pre-exercise condition and "hot wash" critiques are held in all player locations.

The exercise director will contact each lead controller, verify that all objectives have been sufficiently attempted, and obtain concurrence for termination of the exercise. When verification is obtained, the exercise will be terminated, exercise windows closed, and hot wash critiques held. The WCC will receive a termination notification form and transmit it to participating agencies and makes applicable announcements to close the exercise window.

Hot wash critiques will be conducted. 